\section{Organización Campesina en Chile: Reflexiones Sobre su Debilidad Actual ${ }^{1}$}

\author{
Sergio Gómez E.2
}

La situación y el nivel de organización que han logrado los diferentes grupos sociales rurales, como un medio para expresar los intereses de los sectores que representan, es un reflejo sobre el grado de democratización que se ha alcanzado en el mundo rural

A continuación se entregan elementos para evaluar la organización de los diferentes grupos

Basado en el Estudio "Evolución de las Organizaciones Campesinas en Chile: 1990 - 2000". Santiago, julio 2001. Trabajo que contó con el patrocinio de la Oficina de Estudios y Políticas Agrarias del Ministerio de Agricultura de Chile. Por aparecer.

Sociólogo, Doctor en Sociología. Profesor Investigador del Instituto de Ciencias Sociales UACh. rurales en la actualidad, comparándola con la que prevalecía en 1990, fecha en que asume el primer Gobierno de la coalición de Partidos por la Democracia.

Para ubicar el tema de las organizaciones campesinas desde una perspectiva amplia, se le debe ubicar en una doble dimensión: como parte de la sociedad civil y dentro de un conjunto de variables de la sociedad rural en las cuales, las organizaciones hacen parte.

\section{Sociedad civil y organizaciones campesinas.}

La sociedad civil, también conocida como "tercer sector", abarca a las organizaciones que sin tener fines de lucro y con la debida autonomía del mercado y del Estado, son representativas de sectores sociales, de espacios regionales, organizaciones profesionales, organismos no gubernamentales, fundaciones, corporaciones, partidos políticos, iglesias, etc.

Estos componentes de la sociedad civil, pueden facilitar la profundización de la democracia y la integración social a través de posibilitar la participación social, las redes de solidaridad y el desarrollo local. Lo anterior, genera condiciones de gobernabilidad y crea posibilidades para la resolución de conflictos.

El siguiente cuadro, muestra las posibles combinaciones que se pueden encontrar entre el ámbito de lo público y lo privado para dar origen a diferentes sectores.

\section{Variables del sistema rural.}

El enfoque que se propone, considera la variable del sistema rural como una descomposición de 


\section{Cuadro $\mathrm{N}^{\circ}$ 1. Tipos de Combinaciones entre lo Público y lo Privado}

\begin{tabular}{|l|l|l|}
\hline Agentes & Fines & Sector \\
\hline Privados & Privados & Mercado \\
\hline Públicos & Públicos & Estado \\
\hline Privados & Públicos & Tercer Sector \\
\hline
\end{tabular}

Rubem César Fernández. Privado Aunque Público. El tercer sector en América Latina, CIVICUS, Río de Janeiro, 1994, pág. 7

los elementos que forman parte del objeto de estudio: vale decir, las organizaciones rurales, en sus principales componentes: los actores sociales; la estructura agraria y las demandas. Luego define cada uno de ellos y establece las relaciones que se dan entre ellos.

Por lo tanto, cuatro son las categorías que se consideran como un todo, para el análisis del sistema rural. Ellas son:

a) La estructura rural como eje ordenador que predomina en un espacio y momento dados;

b) Los actores sociales que se derivan de dicha estructura;

c) Las organizaciones que dichos actores establecen; $y$

d) Las demandas que estas organizaciones expresan y canalizan.

El siguiente cuadro expresa lo señalado hasta ahora.

\section{Tipología de organizaciones.}

Con el objeto de hacer las distinciones necesarias dentro de la amplia gama de organizaciones campesinas que existen en la actualidad, se recurre a una tipología.

Para ello adoptamos el enfoque neocorporativista que ha propuesto Eduardo Moyano ${ }^{3}$ y que ha aplicado con éxito en diversos estudios en Europa. Este enfoque resulta útil, en la medida que entrega categorías que ayudan a ordenar la información sobre el tema, estableciendo las distinciones que correspondan para diferenciar tipos de organizaciones de acuerdo al tipo de sujeto que la compone, a los fines que persigue al ámbito de la acción y a la existencia o no de formulación ideológica.

Con esas categorías se proponen tres tipos de organizaciones:

a) Profesionales o sindicales

b) Instrumentales o económicas.

c) Gremiales o de representación

\section{Las organizaciones campesinas.}

En el estudio que sirve de base para este artículo se entrega evidencia pormenorizada sobre el debilitamiento de las organizaciones

Cuadro № 2. Variables del Sistema Rural

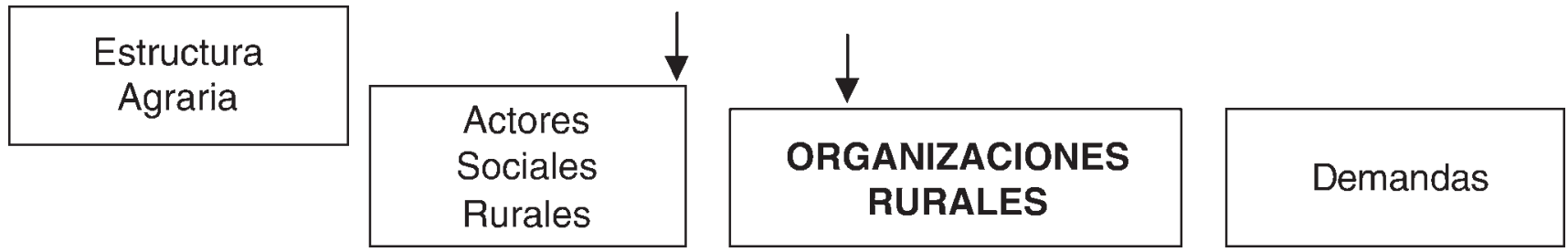

Ver: Sergio Gómez E. La "Nueva Ruralidad”: ¿Qué tan Nueva? (Revisión de la bibliografía y un intento por definir su alcance). Por aparecer. 2001. 
campesinas. A continuación se ofrece una breve síntesis de información agregada.

Al año 1973 la organización sindical tenía 313.700 afiliados, en 1990 llegó a 46.466 y en el año 2000 esa cifra bajó a 36.079 afiliados. Como se puede apreciar, la organización sindical muestra un retroceso con respecto a 1990 y una involución significativa, si se le compara con el desarrollo que había alcanzado en 1973.

Para ubicar mejor el alcance de estas cifras que se comparan, habría que señalar que los 313.700 afiliados del año 1973, correspondían a sindicatos comunales con capacidad de negociación mientras que los 36.079 que existen en la actualidad, se caracterizan:

Por constituir mayoritariamente sindicatos independientes, que no pueden negociar, como lo pueden hacer los sindicatos de empresa.

$>$ Por tener mayoritariamente el carácter de sindicatos vigentes en receso, en lugar de vigentes activos.

$>$ Por encontrarse ubicados en la Región Metropolitana, lo que refleja la carencia de recursos para impulsar la actividad sindical, y no el carácter estratégico de esta zona para el desarrollo del sindicalismo rural.

Con referencia a las organizaciones económicas. Las cooperativas campesinas que en 1973 llegaban a 308 cooperativas con 75.000 socios, en 1990 se registraban 116 cooperativas con 11.947 campesinos afiliados y el año 2000 había 94 cooperativas con 10.684 afiliados. Por lo tanto, las cooperativas campesinas, efectivamente se han debilitado.

Eduardo Moyano E. Acción Colectiva y Corporativismo en la Agricultura Europea. Ministerio de Pesca y Alimentación, Madrid, 1993
Las Asociaciones Gremiales que se crearon entre 1973 y 1990 afiliaban a 25.765 campesinos y en el año 2000 había 29.375 campesinos afiliados a este tipo de organización. Si se compara la situación actual, incluyendo las nuevas organizaciones que agrupan a pequeños agricultores, y se la compara con la realidad existente a comienzos de los años 70 , también se puede observar una fuerte involución.

INDAP ha promovido en los últimos años Empresas Asociativas Campesinas que generalmente se trata de pequeñas organizaciones destinadas a la producción y/o comercialización. Estas incluyen a 13.464 campesinos afiliados

Mientras la situación que muestran las Asociaciones Gremiales hasta el año 1990 reflejan el esfuerzo de organización que realizaron ONG vinculadas al desarrollo rural, su leve crecimiento al año 2000 refleja el apoyo que estas organizaciones recibieron de parte de organismos gubernamentales.

Por su parte las Empresas Asociativas Campesinas, constituyen el nuevo modelo que sistemáticamente impulsó el Gobierno de la Concertación desde mediados de los años 90 en adelante. Desde el punto de vista de la organización campesina, se puede concluir que el resultado es magro, si se le compara con los esfuerzos y recursos comprometidos.

Las organizaciones de mujeres (aproximadamente 2.636 afiliadas) constituyen una novedad dentro del movimiento campesino chileno por el doble hecho de contar con una nueva organización representativa del género y por contar con una institucionalidad estatal para vincularse con las políticas y programas del Gobierno (SERNAM). 
Para terminar este balance, es preciso tener en cuenta que la cifra que se ha construido para el año 1973, solo considera a los afiliados a la organización sindical y a las cooperativas campesinas. En consecuencia, se ha excluido a las organizaciones del sector reformado (federaciones de asentamientos y confederación de las mismas) a los consejos campesinos, etc. por considerar que en algunos casos se daba una afiliación múltiple y podría distorsionar las cifras. Pero, de cualquier manera, la cifra de población rural organizada era mayor que el dato presentado. En cambio para los años 1990 y 2000 se ha considerado al total de las organizaciones existentes, excluyendo las que representan a las etnias.

Entonces, si se compara la realidad que se observa al año 2000 con la de una década atrás, se puede concluir que la organización ha mejorado ligeramente. Pero, si se le compara con la situación que prevalecía a comienzos de los años 70, queda un largo camino por recorrer. En efecto, se puede convenir que, luego de una década de administración de la Concertación, no se ha logrado una modificación sustancial en la situación que dejó como herencia la dictadura militar.

Para comenzar, hay que señalar que la crisis por la que atraviesa la organización social es bastante generalizada, es decir, trasciende a la que se observa en el país y en su sector rural.

En el ámbito mundial, la OIT estima que la sindicalización cayó en un $50 \%$ en la década del 90. Ello se explicaría, en parte, por la caída del mundo socialista que tenía una sindicalización obligatoria y por la propia globalización de la economía contemporánea.
En el plano doméstico, una de las falencias de la transición chilena es el debilitamiento del tejido social que representa y expresa los intereses de los ciudadanos, en los más diversos ámbitos y circunstancias. De ninguna manera, el país ha recuperado la tradición de organización económica y social que tuvo en el pasado, con la excepción de la realidad que muestran los gremios empresariales. Al contrario, en las capas medias y en los sectores populares, la atomización y la privatización de la vida social, son las constantes.

Los datos sobre afiliación sindical, en las diversas ramas de actividad económica en la década analizada, no son mejores que los que muestra la realidad rural. Luego de mostrar una pequeña mejoría los años 1991 y 1992, vuelve a caer a los niveles que mostraba en 1990. Durante el primer año del Gobierno de la Concertación, aumentó el número de afiliados en 19,5\%, pero a partir de 1996 experimenta una caída, situación que la Dirección del Trabajo explica por la crisis económica.

\section{Debilidad de la organización campesina.}

El tema de la vigencia de una organización que represente a los sectores campesinos y de asalariados en el sector rural, sigue teniendo vigencia e importancia. En efecto, las peculiaridades propias del sector rural acrecientan la necesidad que tienen sus habitantes para contar con organizaciones, en la medida que una parte importante de ellos se ubica en poblaciones dispersas.

Antes de dar cuenta del carácter de la crisis es necesario considerar que el movimiento campesino enfrenta la situación de 1973 siendo un movimiento social joven y luego de un período 
de una década donde tuvo un protagonismo muy destacado.

El hecho de resaltar la juventud del movimiento campesino no significa desconocer las raíces que este tiene desde los años 20 del siglo pasado, sino que se quiere destacar el hecho de que en la década 1964 a 1973, tuvo una consolidación y presencia como actor significativo en la sociedad chilena que no lo tuvo antes, ni lo ha recuperado después.

También hay que recordar que esta actividad desplegada por la organización campesina fue un factor central en los conflictos sociales que antecedieron a la quiebra del sistema político en 1973.

Estas dos condiciones - su destacado protagonismo y relativa juventud - llevaron a que la crisis política de 1973 haya sido particularmente dura en este sector.

A continuación se desarrollan tres argumentos que permiten profundizar en la debilidad: la dependencia de las organizaciones, la falta de recursos y la escasa renovación de los dirigentes

Dependencia. La variable dependencia autonomía de un movimiento social en el período en que este se constituye como tal y que se comienza a desarrollar, es una constante que se repite a lo largo de la historia.

En el caso de la constitución de la organización campesina en América Latina la dependencia hacia los sectores urbanos que la promovieron se ha manifestado en todos los países. En efecto, sectores vinculados a los partidos políticos progresistas y a las iglesias, jugaron un papel importante en el impulso inicial para la organización campesina.
Chile no fue una excepción a esta realidad. Los partidos políticos de izquierda y sectores progresistas de la Iglesia Católica estuvieron presentes en el origen de las organizaciones. Además, el aparato de Gobierno en la década 1964 - 1973, a partir de los partidos políticos que lo controlaban, crearon las condiciones para acentuar diferente la relación de dependencia con la organización campesina.

Se puede argumentar que, mediante el financiamiento a que tuvieron acceso las organizaciones, tema que será tratado a continuación, se lograron condiciones para avanzar en una línea de creciente autonomía. Sin embargo, el Golpe de Estado revierte por completo este proceso y las organizaciones vuelven a tener una fuerte relación de dependencia hacia las entidades que les habían dado el impulso inicial, esto es hacia los partidos políticos y hacia la Iglesia Católica. Esto explica, por ejemplo, el rol fundamental que presta a la organización el Departamento Campesino de la Vicaría de la Solidaridad y luego la entidad que lo sucedió, AGRA.

Por último, la creciente fragmentación que se puede observar en las organizaciones en la década analizada, encuentra su explicación en esta regresión hacia situaciones, en algunos casos, de extrema dependencia hacia los partidos políticos.

Escasez de recursos. La organización campesina en Chile, especialmente la sindical contó, en el pasado, con abundantes recursos que le permitió funcionar sin mayores restricciones. La Ley 16.625 de 1967 sobre sindicalización campesina, contenía un mecanismo simple, equitativo y transparente para recaudar, distribuir y fiscalizar importantes 
recursos financieros para asegurar el funcionamiento del movimiento sindical rural y para la capacitación de sus bases y dirigentes. El Fondo de Extensión y Educación Sindical (FEES) es recordado como una entidad que jugó un rol fundamental en el desarrollo de la organización campesina entre 1969 y 1973.

En alguna oportunidad se realizó un calculo sobre los recursos movilizados entre 1969 y $1973 .{ }^{4}$ Se llegó a calcular que el FEES percibió y administró 7,6 millones de US $\$$ y que los sindicatos comunales, las federaciones provinciales y las confederaciones nacionales contaron con 22,6 millones de US \$ para el total del período indicado.

Resulta interesante destacar que estos montos fueron administrados con rigurosidad y nunca se conocieron situación de mal uso o de casos de corrupción que son relativamente habituales en otros países de América Latina cuando se manejan este volumen de recursos. Estos recursos se destinaron a habilitar sedes, contratar profesionales que asesoraban a los dirigentes, vehículos, gastos para cubrir la actividad de los dirigentes, etc.

Con el Golpe de Estado esta situación fue alterada y los dirigentes pasaron a depender de los recursos de la cooperación internacional, que les permitió mantenerse, al menos con un nivel de funcionamiento de subsistencia.

Luego desde 1990 en adelante, la doble condición que logra Chile como país de haber recuperado la democracia y que la economía del país tuvo un desempeño exitoso, llevó a que los recursos provenientes de la cooperación internacional se suspendieran abruptamente, sin que se estableciera un mecanismo de financiamiento alternativo.

Falta de renovación de dirigentes. Para tratar este tema, puede ser útil retomar los comentarios que se han formulado sobre el grado de dependencia y la falta de recursos. En realidad, resulta difícil que nuevos líderes puedan tener interés en integrarse a una organización en estas condiciones.

A ello, hay que agregar la dificultad objetiva que tiene realizar cualquier actividad propia del ámbito de las organizaciones campesinas. Ello, significa que el interés que pueden tener nuevos líderes en ocupar posiciones en las organizaciones en la actualidad, debe ser muy bajo.

Por otra parte, los actuales dirigentes, una mayoría de los cuales vienen ocupando estos cargos desde hace décadas, por responsabilidad no pueden dejarlos y, además, necesitan de una alternativa que resuelva problemas tan simples como urgentes como es la de contar con una actividad que les permita traspasar la experiencia acumulada y dejar esas posiciones para asumir otras tareas, que además les asegure un ingreso estable.

\section{Fortaleza de la organización empresarial.}

A su vez, tanto dentro de Chile como en el resto de América Latina, la debilidad del movimiento campesino en las últimas décadas es una constante, frente a un fortalecimiento de las organizaciones empresariales rurales ${ }^{5}$.

\footnotetext{
5 Ver al respecto del mismo autor Movilizaciones Sociales en el
} Campo. Revista Mensaje № 491, Santiago Agosto de 2000. 
Sin ir más lejos, la Mesa de Diálogo Agrícola, que ha funcionado desde el segundo semestre del año 2000, fue precedida de movilizaciones de los agricultores del Sur y, sobre todo, de amenazas de llevar a cabo movilizaciones públicas y masivas en el caso que no se atendieran sus demandas ${ }^{6}$.

Los Grupos de Transferencia Tecnológica, como organización profesional, las organizaciones instrumentales como los PROFOS y organizaciones de productores y las organizaciones de representación como son la Sociedad Nacional de Agricultura (SNA) y el Consorcio de Sociedades Agrícolas del Sur (CAS), se mantienen en plana actividad.

Esta realidad no es nueva. En el plano local, sin ir más lejos, se recordará el conflicto que se suscitó a mediados de 1979, en pleno régimen militar, a propósito de los aranceles para la leche importada. Los agricultores, encabezados en aquella época por el legendario Domingo Durán, solicitaban la reposición de un arancel que se aplicaba a la leche importada, para impedir la quiebra de la industria lechera nacional. En las negociaciones, los argumentos de la autoridad económica - siempre la misma - planteaban que no resultaba justo encarecer el producto a los consumidores, mientras los agricultores presionaban - con los mismos argumentos de ahora - en la necesidad de mantener el arancel. En medio de las negociaciones, un asesor del Ministro de Economía sostuvo que, si no lograban las condiciones de competitividad necesaria, debían salir del mercado y sentenció con la histórica frase, que encendió la mecha del conflicto: "que se coman las vacas".

Idem. Anterior, donde se analizan las amenazas de movilizaciones que precedieron a la instalación de la Mesa de Diálogo Agrícola.
También hay que mencionar que hace seis años, se realizó la llamada "Asamblea de Agricultores de San Carlos" en el mes de Julio de 1995. En la ocasión, convocados por la SNA, más de 20.000 agricultores hicieron una demostración de fuerza en la Media Luna de San Carlos, donde mostraron una poderosa organización que les permitió subir el volumen de la voz en sus peticiones, logrando imponer una parte importante de sus puntos de vista.

Recientemente, el 13 de julio de 2001 se realizó otra movilización en el mismo lugar que congregó a una cantidad similar, no sólo a agricultores entre la VII y X Regiones, sino además a comerciantes y transportistas.

También, es necesario recordar la movilización que realizaron los gremios empresariales agrícolas en 1996 para protestar por la incorporación de Chile al MERCOSUR y por las consecuencias que ello tendría para la agricultura del país. Recordemos que en la ocasión, se hizo un simulacro de un "funeral a la agricultura" provocando cortes en las principales carreteras del país. En esta movilización lograron un apoyo decidido de todos los partidos políticos con representación parlamentaria. Estas movilizaciones terminaron con la creación de un fondo destinado por el Gobierno para acrecentar la productividad y compensar los efectos negativos de la incorporación al MERCOSUR.

Como se ha dicho, estos hechos no son de ocurrencia sólo en Chile. Suceden en Europa, en los Estados Unidos y en casi todos los países de América Latina. Aunque los ejemplos se podrían multiplicar, solo se hará referencia a tres casos: México, Argentina y Uruguay. 
En México, en 1993 nace en el Estado de Zacatecas el movimiento conocido como "el Barzón", que luego se expande a todo el país. El barzón, corresponde a una parte del yugo que usaban los bueyes de trabajo y dio origen a una conocida canción popular mexicana de la época de la revolución agraria de 1910, en la que se denunciaban las injusticias de la hacienda. El movimiento surge en los momentos en que México concluye las Negociaciones del Acuerdo del NAFTA, que entró en vigor en Enero de 1994, lo que tornó más difícil las condiciones de los productores agrícolas mexicanos.

Esta situación llevó a una seria crisis de endeudamiento, la que se agravó con una devaluación que significó que el precio del dólar se doblara, con lo que las deudas, especialmente aquellas asumidas en dólares, se duplicaron.

Las acciones desarrolladas por el movimiento el Barzón, son directas (bloqueo de carreteras, toma de oficinas de bancos, etc.) sin violencia y en los límites de la legalidad, con el objeto de denunciar el carácter de usura que tenía la deuda, llamando a no pagarla.

El movimiento se desarrolló protestando en contra las consecuencias de la competencia externa; los efectos de la desregulación del Estado; y la política financiera que favorecía al sistema bancario, en desmedro de los productores. Dicha política ha conducido a una perdida de rentabilidad de la actividad agrícola y a una acumulación las carteras vencidas, embargos y remates de los predios.

Como se ha dicho, sus acciones están dirigidas a no pagar las deudas consideradas injustas y detener los embargos y remates. El movimiento nació en el campo y luego se extendió hacia áreas urbanas. Su consigna planteaba: "Debo no niego, pago no tengo. Debo no niego, pago lo justo".

Por su parte en Argentina, los gremios rurales tienen larga experiencia en Paros Agrarios, en que los agricultores se movilizan para protestar contra la aplicación de nuevos impuestos; solicitar la refinanciación de la deuda y la falta de apoyo gubernamental al sector afectado por la fuerte caída en los precios.

En 1995 se comienza a estructurar el Movimiento de Mujeres Agropecuarias en Lucha, MML, y se consolida en 1998. Se trata de una organización compuesta por mujeres de agricultores que se dedica a suspender la ejecución de remates judiciales de predios que se encuentran endeudados con los bancos. El MML nace como una acción espontánea de las mujeres de un sector de colonos donde un factor clave en el surgimiento de la organización es el endeudamiento del sector provocado por la apertura indiscriminada al mercado mundial. De acuerdo al MML, sólo el $30 \%$ del total de la deuda de los productores corresponde al capital inicial de la deuda, el $70 \%$ restante corresponde a intereses, gastos administrativos, etc.

Finalmente en Uruguay, el conjunto de las organizaciones rurales gremiales logró un acuerdo en torno a la Intergremial de Productores de Carne y Lana y organizaron una marcha sobre la ciudad de Montevideo. La Marcha, desarrollada en abril de 1999 congregó a 10.000 personas con vehículos, tractores, carros, caballos, etc. generando asombro y simpatía. Se elaboró un Programa de Emergencia y se fijaron 30 días para obtener respuesta. Las reivindicaciones son siempre similares: que se le devuelva "la competitividad, 
la rentabilidad y la viabilidad al agro". Luego, a mediados de junio de 1999, nuevamente se movilizan miles de agricultores en masivas concentraciones en sus tractores con productos cargados y montando caballos, en 21 ciudades, simultáneamente. También exigían rebaja de impuestos y condonación de la deuda.

Como se puede apreciar las movilizaciones empresariales rurales en el caso chileno, no constituye una excepción. El tema recurrente de todas estas movilizaciones es el nivel de protección que se reclama para la mantención de la agricultura tradicional.

Lo que efectivamente se encuentra en juego es la mantención de una ruralidad expresiva en el país, al modo como lo hacen los países desarrollados.

Como lo plantean en el caso de Chile los dirigentes del CAS, si se aplica el modelo en su versión más ortodoxa, simplemente la zona sur del país se convertirá en un gran bosque y el tercio de chilenos que actualmente ocupa y trabaja en su territorio, migrará hacia las grandes ciudades. Este es el sentido de la movilización que se realizó en San Carlos en julio del año 2001.

Se ha descrito, con algún detalle, la realidad de las movilizaciones empresariales como un fenómeno que tiene vigencia más allá de la realidad de Chile, para ubicar la realidad de las organizaciones rurales en el contexto global de América Latina.

\section{Frustración de los dirigentes campesinos.}

Frente a la debilidad de las organizaciones campesinas y a la fortaleza de las empresariales, es necesario dar cuenta sobre el estado de ánimo que prevalece en la actualidad entre los dirigentes campesinos.

El grado de frustración de los dirigentes tiene como referente su pasado reciente; las promesas que recibieron de parte de los dirigentes de los partidos políticos; y del papel que ellos jugaron en los años de dictadura para recobrar la democracia.

La mayoría de los dirigentes había participado de los procesos masivos de organización campesina y de reforma agraria que se desarrolló en la década entre 1964 y 1973.

La percepción que estos dirigentes campesinos construyeron sobre la realidad de la organización campesina en el campo de aquel período se puede expresar del siguiente modo.

Durante aquella década, los pequeños agricultores y sobre todo los asalariados rurales, tuvieron la posibilidad de ser considerados "ciudadanos". Tras esta percepción, hay una gran valoración por lo que genéricamente se recuerda como la época en que se logra la "dignidad" para este sector. Ello se expresa en dos actividades fundamentales: una es el establecimiento de un conjunto de organizaciones campesinas que, estimuladas desde el aparato de Gobierno, le otorgaron a este sector un protagonismo que jamás había alcanzado; la segunda, es un proceso de reforma agraria que pone fin a un sistema ineficiente e injusto, entregando posibilidades de desarrollo a los asalariados rurales que participaron en la reforma, con acceso a recursos hasta entonces inalcanzables, entre ellos, tierra de buena calidad. 
En otras palabras, la percepción que tenían los dirigentes, es que durante este período la sociedad civil rural se fortaleció en forma muy significativa.

Pues bien, el Golpe de Estado fue percibido como el comienzo de un paréntesis, que simplemente interrumpía, con una violencia inesperada un proceso que, de seguro, tendría continuidad, una vez que los militares abandonaran el poder.

Esta es la visión bastante generalizada que se podía encontrar entre los dirigentes campesinos que se forjan como líderes en la década 1964 - 1973.

Durante la década de los 80 , cuando se avanza en un diagnóstico sobre los cambios ocurridos durante el régimen militar y se comienza a establecer los elementos de una plataforma de programa para un gobierno post autoritario, el tema de la reforma agraria cobra nuevamente vigencia. Mientras para la mayoría de los dirigentes campesinos, se trataba de una tarea pendiente que había que retomar una vez conquistada la democracia, para muchos dirigentes y analistas, la reforma agraria era un tema del pasado. Estos argumentaban que en el contexto de los cambios provocados por la contrarreforma agraria, la apertura del comercio exterior y la creciente transnacionalización de las actividades agropecuarias, las banderas de lucha para el movimiento campesino eran otras, y que la reforma agraria como reivindicación, carecía de sentido hacia el futuro.

En esta discusión, se terminó por imponer la opinión que la reforma agraria no era un tema que estuviera a la orden del día, pero, siempre se mantuvo la idea de que el restablecimiento del movimiento campesino, estaba fuera de toda duda, en cuanto a la vigencia y urgencia que tendría este tema para los Gobiernos post autoritarios.

Por lo tanto, se puede suponer que había una alta expectativa sobre una rápida reactivación de las organizaciones campesinas - de todo tipo - y un impulso a las movilizaciones campesinas cuando se inician los Gobiernos de la Concertación. En definitiva, había llegado el momento en que la sociedad civil en el campo, sería fortalecida.

El siguiente testimonio de un dirigente de una Federación Provincial de Sindicatos, con una larga experiencia, es representativo de un amplio sector de dirigentes campesinos:

"La esperanza de cambios, luego de 17 años de dictadura comienza a gestarse a raíz de la Campaña Política del Plebiscito por el NO de 1988. En esta campaña la Federación juega un rol protagónico en la medida que en su propio local funciona el Comando Provincial de la Campaña por el NO, expresada en la Concertación de Partidos por el NO. Su participación en la Campaña consistió en anunciar públicamente que la situación vigente hasta el momento podía cambiar significativamente. Se trataba de reconquistar la libertad personal, la libertad sindical que significaba cambios en las formas de contratación, de negociación, en la salud, en la educación, etc."

Los trabajadores rurales afiliados a la organización recibieron este anuncio de parte de los dirigentes de la Federación y de los dirigentes de los partidos políticos. Se movilizaron con entusiasmo y lograron un amplio respaldo de sus bases para el voto por el NO. En definitiva se 
trataba de terminar con el Plan Laboral impuesto por la Dictadura. Luego en 1989, se jugaron por la elección del Candidato Presidencial de la Concertación de Partidos por la Democracia y por los parlamentarios de modo de tener los mecanismos administrativos y legislativos para cambiar la situación que prevalecía en el campo.

Durante la campaña presidencial y parlamentaria, se reunieron los dirigentes campesinos de todo el país en Talca durante tres días con el objeto de plantear la plataforma del programa en cuanto a la sindicalización campesina y medidas de apoyo para la pequeña agricultura. Las demandas de los dirigentes campesinos de organizaciones ligadas a los partidos políticos integrantes de la Concertación fueron entregadas al candidato presidencial Aylwin y a los postulantes al parlamento de la coalición.

En resumen, se plantearon dos demandas:

1) Reponer en plenitud la ley 16.625 sobre sindicalización campesina, que fue la ley que es recordada como el instrumento que otorgó dignidad al campesino. Esto incluía tener sindicatos comunales fuertes, con dirigentes con capacidad de dirigir, con fuerza para negociar, con causales precisas de despidos y disponer de financiamiento por ley para permitir que las organizaciones puedan funcionar.

En el caso que ello no fuera posible reeditar la Ley con su mismo articulado, como se reclamaba, se planteó la posibilidad de que los principios fundamentales de esta Ley se mantuvieran.

2) También se planteó como una medida de reparación para aquellos campesinos que habían sido víctimas de discriminación durante el proceso de reforma agraria, básicamente aquellos afectados por el DL 208. Para ello se planteó establecer un "Fondo de Tierras", con tierras fiscales y con reservas que se encontraban en poder del Estado. Ello se veía como una solución a problemas pendientes de un fuerte contenido simbólico.

Vale la pena consignar que las expectativas no se referían a reconstituir situaciones que habían quedado atrás hacía 18 años, sino de rescatar elementos que realmente pudieran ser mostrados como señales concretas de superación de injusticias y de ruptura, con respecto a las políticas implementadas durante la dictadura militar.

En la medida que ninguna de estas demandas fue atendida, el sentimiento de frustración se ha vuelto generalizado entre los dirigentes campesinos.

\section{Cambios en el entorno}

Los cambios en el entorno son sustantivos y tienen mucho que ver con la situación de las organizaciones campesinas en la actualidad.

\section{La nueva realidad del entorno sindical}

En el caso del entorno de la organización sindical los cambios son profundos. Hay que tomar en cuenta la de la discusión que ocurre en la actualidad y que da cuenta de los efectos de los cambios tecnológicos en las formas de organización de la producción y en la organización del trabajo. Lo anterior termina por redefinir el papel de los principales actores en las empresas, entre ellos sus trabajadores y las formas de integración en ellas. 
Ellos tienen una base estructural determinante y deben concluir en un cambio cultural que modifique las imágenes que los empresarios tienen de los asalariados; la que éstos tienen de aquellos; y la visión que ambos, finalmente deben tener sobre la empresa.

Dada la importancia que tiene el tema y la forma vulgar en que ha sido tratado por diversos lideres empresariales y de asalariados, se plantea la necesidad de abordarlo en forma relativamente sistemática.

Los estudios que se refieren a este tema ${ }^{7}$, lo ubican desde la perspectiva de la transición desde la forma de producción fordista a la posfordista. Se plantea que se enfrenta un nuevo paradigma productivo ${ }^{8}$ y este recibe nombres tales como posfordismo, neofordismo, especialización flexible, producción ligera, etc. Se llega a esta condición a partir de la década del 70 cuando colapsa la lógica taylorista fordista. Mientras Taylor introduce la estandarización de los procesos de trabajo, Ford introduce la cadena de montaje, donde la cadena transportadora moviliza las piezas sobre la cual intervienen los obreros. Este esquema lleva a la disociación entre la concepción y la ejecución de los trabajos. También se llega a la conclusión que el sistema taylorista - fordista no resuelve adecuadamente la relación virtuosa entre el aumento de la productividad, de los salarios y de los beneficios. Finalmente, las economías nacionales pierden relevancia y autonomía frente al proceso de globalización.

Ver, por ejemplo, Laura Palomares y Leonardo Mertens. El movimiento sindical ante los cambios en la práctica productiva. En: Economía \& Trabajo, Año I, No 1. Enero Junio 1993.

8 Cecilia Montero. Trabajo, Empresa y Sociedad. Del trabajo obrero a la competitividad de la empresa. En Dimensiones Actuales de la Sociología. Manuel Antonio Garretón y Orlando Mella, Editores. Santiago, 1995.
El nuevo esquema considera una escala mas reducida de la producción, dando prioridad a la demanda, involucrando a los trabajadores, desarrollando relaciones de cooperación con los empresarios, y productos mas diversificados. El núcleo central de la empresa no solo es el capital y la tecnología, sino la dimensión social de la producción. Cada etapa de la producción se debe orientar a satisfacer al consumidor al mínimo costo posible.

En primer lugar, hay que reconocer que en la gran mayoría de las empresas agropecuarias y en muchas agroindustriales no existe una instancia institucional donde este tema se pueda tratar, como podría ser una gerencia de personal.

En segundo lugar, el tema de las relaciones laborales, en el caso del sector agropecuario en Chile, se encuentra enturbiado por traumas y fantasmas del pasado, que tienen que ver con las movilizaciones sociales y el proceso de reforma agraria que se desarrollaron en la década de 1964 - 1973. Ancestrales desconfianzas y conductas irracionales perjudican la posibilidad de avanzar en la modernización de este sector.

En tercer lugar, hay que afirmar la potencialidad que tiene para la empresa el logro de relaciones laborales equilibradas y justas. Ello, como plantea el autor recién citado, no implica la desaparición de los conflictos, que siempre existirán, sino que se deben crear los mecanismos para resolverlos. Además, no es raro que en aquellas empresas donde se logra la identificación de los trabajadores con los objetivos de la empresa, tienen una visión positiva de los impactos de las innovaciones tecnológicas. 
Uno de los temas fundamentales de la modernización de las relaciones laborales es la flexibilidad del mercado de trabajo. En efecto, "cuando se habla de flexibilización del mercado laboral, la imagen que surge es que se trata de recortes salariales, facilitar los despidos, reducir costos salariales indirectos, desrregular el mercado liberal y privatizar la relación contractual entre el trabajador y el empresario". ${ }^{9}$

Sin embargo, también se puede pensar en una flexibilización concertada donde se privilegie la calificación y la motivación de los trabajadores, como condición de avanzar en la competitividad de la empresa.

El problema de fondo para avanzar en este tipo de modificaciones, muchas veces, tiene que ver con experiencias del pasado y que todavía son verdaderos fantasmas que impiden introducir cambios donde se establezcan un nuevo tipo de relaciones sociales entre empresarios y trabajadores. Viejas desconfianzas entraban la posibilidad de avanzar en estos ámbitos.

Resulta curioso que procesos que ocurrieron hace 30 años se mantengan vigentes en la memoria colectiva de un sector importante del empresariado agrícola. Y, lo que es peor, es que resulta frecuente que, a partir, de situaciones que tiene solo un componente de realidad, se construyen verdaderas fábulas que terminan transformándose en realidades. El asunto de fondo es que, la percepción que se tiene sobre las movilizaciones campesinas que terminaron con el proceso de reforma agraria, se mantiene como un referente que determina conductas que impiden construir nuevas relaciones sociales entre empresarios y asalariados. Este no es el

Idem. anterior. caso de empresarios que se encuentran ligados a firmas transnacionales.

\section{La nueva realidad del entorno de la pequeña agricultura.}

Es necesario superar el enfoque segmentado para el desarrollo de la pequeña agricultura. Se entiende por enfoque segmentado aquel que considera el desarrollo de la organización campesina en una perspectiva de aislar los grupos carentes de otros sectores y de considerar únicamente el desarrollo agrícola. Esto ha llevado a que las organizaciones campesinas se encuentren integradas exclusivamente por aquellos que comparten una misma situación socioeconómica y se dedican a la actividad agropecuaria.

Una visión de desarrollo local que considere como unidad un determinado territorio y no determinados predios, podría integrar a las organizaciones a campesinos no necesariamente los más pobres, sino también a estratos más acomodados y a personas con capacidad de emprendimiento. Experiencias que se desarrollan en el Valle de Petorca muestran relaciones virtuosas entre campesinos asignatarios derivados de la reforma agraria con empresarios modernos y emprendedores ${ }^{10}$.

La estrategia de segmentación es una variante de la estrategia de focalización de los programas que es muy válida cuando se trata de programas que tienen como objetivo la distribución de recursos, pero no resulta una estrategia adecuada cuando se trata de programas que persiguen la promoción de grupos. En el primer caso resulta

\footnotetext{
10 Ver al respecto: Ramón Downey. Nuevas Formas de Asociación de Productores en Petorca. Informe de Consultoría. Santiago, 2000 .
} 
conveniente para que los recursos lleguen efectivamente al grupo objetivo; en el segundo el hecho de aislar a los grupos menos favorecidos de otros que han logrado superar esa condición, significa privarlos de un contacto para conocer ejemplos que serían útiles de emular.

Además una visión más moderna del desarrollo rural debería considerar la dimensión agropecuaria como un componente más de las posibles actividades que se podrían desarrollar.

\section{Las posibles salidas.}

Para avanzar en reestructurar la organización campesina en Chile es necesario constituir un escenario, elaborar una agenda y definir los principales participantes de la discusión.

El escenario en el que se debe dar la discusión debe considerar dos niveles. Por un lado, debe haber una instancia política donde se tomen las decisiones básicas, entre ellas un detalle de la agenda, que se debatirá. También deberá consensuar la nómina de un equipo técnico que debería elaborar las opciones de propuestas que deberían ser adoptadas en el nivel político.

Resulta de vital importancia que la agenda considere las distinciones entre los diversos tipos de organizaciones campesinas y de asalariados, que se hagan proposiciones legales y prácticas para su funcionamiento, en definitiva, que se plantee los puntos centrales que se deberían tratar para reactivar las organizaciones.

Es el Gobierno quién debe definir en una primera etapa a los participantes en esta actividad. Concretamente se sugiere que lo haga el Ministerio de Agricultura, con el apoyo técnico interlocutor a INDAP ya que los temas se desvían en función del objetivo de INDAP, del apoyo de la pequeña agricultura que, con ser un tema importante, no es el único que interesa al conjunto de las organizaciones campesinas. Tampoco se estima conveniente aprovechar la Mesa de Dialogo Agrícola, en la medida que ella se encuentra abocada a temas que trascienden el de las organizaciones campesinas.

En consecuencia, se sugiere que ODEPA convoque a un conjunto de personas directamente involucrados en el tema, como son:

- Dirigentes campesinos

- Asesores de las organizaciones

- Funcionarios de Gobierno INDAP, Dirección del Trabajo, Ministerio Secretaria General de la Presidencia, Dirección de Organizaciones Sociales de la Secretaria General de Gobierno, etc.

- Encargados rurales de los partidos políticos

- Otros relevantes; Académicos, funcionarios internacionales de IICA, FAO, etc.

Estos recibirían una síntesis del resultado del estudio y definirán los términos de referencia para que grupos técnicos elaboren propuesta específicas, las que serían posteriormente sancionadas por este mismo grupo de personas.

\section{Reflexión final.}

Como se ha planteado, el proceso de modernización parcial que afecta a la agricultura no solo implica una dualidad, en el sentido que coexiste un sector moderno junto a otro tradicional, sino que también dentro del sector moderno se puede observar una modernización parcial en el ámbito de las relaciones laborales. 
La democracia insuficiente se refleja en la falta de mecanismos de participación y en el fraccionamiento y la extrema debilidad de la organización campesina.

El fortalecimiento de la red de organizaciones representativas en el sector agropecuario es fundamental para desarrollar la sociedad civil como un medio para avanzar en la democratización de la sociedad rural.

Para terminar se plantea que la posibilidad de avanzar en la democratización real de la sociedad rural pasa por el desarrollo y fortalecimiento de la organización campesina. Esta es una condición para que puedan existir relaciones de colaboración entre asalariados y empresarios, lo que implica reconocer la existencia del otro para su propio desarrollo, y para que los asalariados rurales, campesinos y empresarios puedan participar en las instancias locales, regionales y nacionales que tengan que ver con los problemas que los afectan a todos. 


\section{Bibliografía}

Rubem César Fernández. Privado Aunque Público. El tercer sector en América Latina, CIVICUS, Río de Janeiro, 1994

Sergio Gómez E. Instituciones y Procesos Agrarios en Chile, Ediciones FLACSO, Santiago 1982.

Sergio Gómez E. La "Nueva Ruralidad": ¿Qué tan Nueva? (Revisión de la bibliografía y un intento por definir su alcance). Por aparecer. 2001

Cecilia Montero. Trabajo, Empresa y Sociedad. Del trabajo obrero a la competitividad de la empresa. En Dimensiones Actuales de la Sociología. Manuel Antonio Garretón y Orlando Mella, Editores. Santiago, 1995.

Eduardo Moyano E. Acción Colectiva y Corporativismo en la Agricultura Europea. Ministerio de Pesca y Alimentación, Madrid, 1993.

Laura Palomares y Leonardo Mertens. El movimiento sindical ante los cambios en la práctica productiva. En: Economía \& Trabajo, Año I, No 1. Enero Junio 1993. 